\title{
Candida albicans Biofilm Inhibition by Ethnobotanicals and Ethnobotanically-Synthesized Gold Nanoparticles
}

\author{
Khristina G. Judan Cruz ${ }^{1 * t}$, Eleonor D. Alfonso ${ }^{2 \dagger}$, Somar Israel D. Fernando ${ }^{1}$ and \\ Kozo Watanabe ${ }^{3,4}$ \\ ${ }^{1}$ Department of Biological Sciences, College of Science, Central Luzon State University, Science City of Muñoz, Nueva Ecija, \\ Philippines, ${ }^{2}$ College of Agriculture, Nueva Ecija University of Science and Technology, Nueva Ecija, Philippines, \\ ${ }^{3}$ Department of Civil and Environmental Engineering, Ehime University, Matsuyama, Japan, ${ }^{4}$ Center for Marine \\ Environmental Studies (CMES), Ehime University, Matsuyama, Japan
}

OPEN ACCESS

Edited by:

S. Sivakumar,

Pusan National University,

South Korea

Reviewed by:

Fahad Alam,

Khalifa University, United Arab

Emirates

Shakir Khan

University of Massachusetts Boston,

United States

*Correspondence:

Khristina G. Judan Cruz

kjcruz@clsu.edu.ph

${ }^{\dagger}$ These authors share first authorship

Specialty section:

This article was submitted to Antimicrobials, Resistance

and Chemotherapy,

a section of the journa

Frontiers in Microbiology

Received: 07 February 2021 Accepted: 20 April 2021

Published: 24 May 2021

Citation:

Judan Cruz KG, Alfonso ED, Fernando SID and Watanabe K (2021)

Candida albicans Biofilm Inhibition by

Ethnobotanicals and

Ethnobotanically-Synthesized Gold

Nanoparticles.

Front. Microbiol. 12:665113.

doi: 10.3389/fmicb.2021.665113
The virulence and drug resistance of globally prevalent Candida albicans has presented complications toward its control while advances in effective antivirulence drugs remain critical. Emerging methods are now being evaluated to facilitate development of novel therapeutic approaches against this pathogen. This study focuses on the biofilm formation inhibition of ethnobotanical crude extracts and the use of nanotechnology through the ethnobotanically-synthesized gold nanoparticles to control C. albicans. Control on biofilm formation was compared using crude extracts (CEs) and biologically synthesized gold nanoparticles (CEs + AuNPs). Significantly lower biofilm formation was exhibited in thirteen (13) CEs and fourteen (14) CEs + AuNPs. Biofilm-linked genes BCr1 and HSP9O expression were consequently downregulated. Higher biofilm inhibition activity was noted in some CEs + AuNPs compared to its counterpart CEs. This study emphasizes the biofilm inhibition activity of ethnobotanicals and the use of nanoparticles to enhance delivery of compounds, and points to its prospects for developing anti-pathogenic drugs without evolving resistance.

Keywords: Candida, biofilm, quorum sensing, gold nanoparticles, ethnobotanicals, Bcr1, HSP9O

\section{INTRODUCTION}

Candida albicans is a globally prevalent pathogen owing to its capability to survive at diverse biotic and abiotic sites (Mathe and Van Djick, 2013; Gao et al., 2016; Lee et al., 2018) with the ability to cause an array of infections that ranges from superficial to life threatening. Candida infections, commonly known as candidiasis or candidosis (Douglas, 2003; Moran et al., 2012), can occur as a consequence of its ability to develop a biofilm, a quorum sensing (QS) mechanism associated with its pathogenicity (Silva et al., 2011; Pfaller, 2012). The complexity of its biofilm offers virulence through its three-dimensional structure and innate drug resistance (Pereira et al., 2020) while withstanding host immune responses (Lee et al., 2018), thus, requiring multifaceted scheme for its control.

This high level of tolerance to multiple drugs (Duo et al., 2010; Gao et al., 2020) contribute complications to control this pathogen, and this pose serious threats to healthy and medically 
compromised individuals that often lead to severe fatal infections (Hall-Stoodley et al., 2004; Lohse et al., 2018). Control of Candida through commercial antifungal drugs such as triazole drugs and echinocandins (Cruz et al., 2007; Peman et al., 2009) is practiced, but not without the consequences of developing fungal resistance and reduced susceptibility. Administration with these antifungal drugs inevitably produce evolving strains throughout long-term treatment (Cruz et al., 2007), hence, the increasing incidence of drug-resistant Candida.

To address emerging virulence and fungal resistance, Quorum Sensing (QS) mechanisms are now targeted. Quorum sensing is a cell-to-cell communication system that coordinate virulence and gene regulation through specific signal molecules that enable bacteria to adapt to changing conditions. Targeting this QS system reduces microbial virulence without disabling growth, thereby counteracting microbial resistance (Maeda et al., 2012; Zhong and $\mathrm{He}$, 2021) brought about by selective pressure through overuse and mishandling of antipathogenic drugs (Borges and Simoes, 2019; Lewis, 2020; Zhong and He, 2021). Current therapies are limited and this situation has paved for the discovery of new antipathogenic agents (Duo et al., 2010). Recent studies have shown that plant metabolites offer essential agents to target drug-resistant microorganisms (Lee et al., 2018).

Among the promising sources of QSI (Quorum Sensing Inhibition) agents is a group of unexplored plants, the ethnobotanicals. These are plants that are utilized by ethnic groups for the treatment of diseases. Majority of the ethnic communities are geographically isolated and mostly depend on natural products for their medicines. One of the diverse ethnic communities in the Philippines is the Ilongot-Egongot. As one of the significant ethnic groups in the Philippines, they largely reside in the biologically diverse areas of Aurora, in the island of Luzon, Philippines. These areas comprise a deep, vast source of plants for medicinal use. Their use of ethnobotanicals, typical of the other ethnic tribes, are transferred from one generation to another, and thus, of cultural importance. Until recently, ethnobotanical evaluations are limited and this represents a recent group of plants that have gained interest for evaluating antipathogenic sources. The prospects of discovering natural QSI compounds from ethnobotanicals are evident in few existing researches that provide scientific validation of its potential use. These plants are powerful sources of natural QS inhibitors essential for the development of safe, novel therapeutic and antipathogenic agents (Fernando and Judan Cruz, 2020). Recently, the Ilongot-Eǵongot ethnobotanicals evaluated in this study have been demonstrated to possess QS inhibition properties against pathogenic bacteria such as Pseudomonas aeruginosa (Velasco et al., 2020; Santos et al., 2021), Staphylococcus aureus (Salamanca et al., 2019), Aeromonas hydrophila (Fernando and Judan Cruz, 2020), and Streptococcus agalactiae (Fernando et al., 2020). QSI actions of these plants against pathogenic fungi such as Candida have not yet been explored.

The formation of biofilm in pathogens is mediated by a network of genetic mechanisms. Among the key genes that are linked to biofilm adhesion, dispersion and regulation in C. albicans are the Bcrl and Hsp90. Expression of these genes impacts the formation and quality of the biofilm. Bcrl is among a system of transcription regulators that facilitates the formation of biofilm in C. albicans (Nobile et al., 2006; Mayer et al., 2013). As a transcription regulator, $B c r 1$ directs functionally associated target genes that can eradicate a function that is carried out by redundant genes (Fanning et al., 2012). Bcr 1 and its downstream genes are expressed during adhesion of C. albicans on the substrate (Nobile et al., 2006) and this adhesion impacts the arrangement of the polysaccharide matrix (Douglas, 2003). The heat shock proteins (HSPs) unique to fungi and not present in humans have surfaced as a promising drug target for C. albicans management (Mayer et al., 2013). HSP90, a major HSP, is a key regulator in biofilm formation and virulence by suppressing dispersion (Robbins et al., 2011) and intricate cell signals (Pearl and Prodromou, 2006; Shapiro et al., 2009). HSP90 also controls temperature- dependent morphogenesis by suppressing cAMP-PKA signals (Robbins et al., 2011). It also allows for the emergence of resistance to majority of existing antifungals (Robbins et al., 2011). Downregulation of these genes affects the formation, adherence and dispersion of the complex biofilm and its multi- dimensional polysaccharide matrix (Douglas, 2003). Hence, by negatively affecting $B c r 1$ and $H s p 90$ expression, fungal communication will be inactivated and consequently, virulence (Rasmussen and Givskov, 2006).

For a more efficient delivery of anti-pathogenic drugs from the natural metabolites, nanotechnology has gained substantial interest and relevance in drug design. Nanoparticles are used in drug delivery for an efficient transport of soluble drugs (Kamat et al., 2002; Daniel and Astruc, 2004) targeted to a specific site and bioavailability. The use of biosynthesized nanoparticles to enhance treatment of diseases increases the relay of drugs and subsequently enhances treatment of diseases due to their reduced dimensions, its efficiency due to their extremely small size and large relative surface area (Hentzer et al., 2003; Srisawat, 2007; Khatami et al., 2017).

This study evaluated the QSI properties of the ethnobotanical crude extracts as well as the biosynthesized nanoparticles using the Ilongot-Eǵongot ethnobotanicals to control biofilm formation and QS-related gene expression.

\section{MATERIALS AND METHODS}

\section{Collection of Plant Samples and Ethanol Extraction Procedure}

Ethnobotanicals surveyed by Balberona et al. (2018) at the Ilongot-Eǵongot community of Maria Aurora, Aurora, Philippines were evaluated. Necessary permits from the provincial and tribal chieftains as well as from the Department of Natural Resources (DENR), Philippines were obtained for the collection of plant samples. Voucher specimens were identified by an expert taxonomist and deposited at the Department of Biological Sciences, Science City of Muñoz, Nueva Ecija, Philippines. Plant samples were collected, sterilized, air-dried and ground. Fifty grams (50 g) of ground leaf were soaked in $500 \mathrm{ml}$ of $80 \%$ ethanol in a covered flask for $72 \mathrm{~h}$ and was filtered. The alcohol was removed through a rotary evaporator. The crude extracts were sterilized by centrifugation of the mixture 
at $10,000 \times \mathrm{g}$ for $30 \mathrm{~min}$ followed by membrane filtration using Acrodisc $25 \mathrm{~mm}$ Syringe Filter. The sterile extracts were kept at $2-8^{\circ} \mathrm{C}$ prior to use (Srisawat, 2007). Plant extracts evaluated were: Hydrocotyle vulgaris (leaf), Eluesine indica (root), Eluesine indica (leaf), Mikania micrantha (leaf), Dillenia philippinensis (leaf), Dillenia philippinensis (bark), Ceiba pentandra (leaf), Cymbopogon winterianus (leaf), Senna alata (leaf), Urena lobata (leaf), Premna odorata (bark), Premna odorata (leaf), Stachytarpeta jamaicensis (leaf), Diplazium esculentum (leaf), and Phyllanthus urinaria (leaf).

\section{Biological Synthesis of Gold Nanoparticles}

Gold chloride (Sigma Aldrich) was prepared at the $10^{-3} \mathrm{M}$ concentration with sterilized Milli-Q (Merck) water. For the synthesis, $5 \mathrm{ml}$ of crude extract was mixed with $45 \mathrm{ml} 10^{-3} \mathrm{M}$ gold chloride. The bottles were incubated in dark condition under room temperature with consistent stirring through a magnetic stirrer for $60 \mathrm{~min}$ until a pink red color was attained. This change in color indicates the synthesis of AuNPs. To assess the stability of nanoparticles, the AuNPs obtained from the solution were purified by centrifugation at 4,000 rpm for $20 \mathrm{~min}$ and dispersed in deionized water. The water suspended NPs were frozen at $30^{\circ} \mathrm{C}$ overnight and were kept under vacuum for $24 \mathrm{~h}$ for drying.

\section{Preparation of Fungal Culture}

Pure culture of C. albicans ATCC 9002 was obtained from UPLB BIOTECH, Los Baños, Laguna, Philippines. Corn meal agar was used to revive and maintain cultures of $C$. albicans. For the subsequent assays, $24 \mathrm{~h}$ fungal culture was suspended in sterile saline solution $(0.9 \% \mathrm{NaCl})$ at $26-30^{\circ} \mathrm{C}$ and the turbidity was adjusted to $1.0 \mathrm{M}$ McFarland standard.

\section{Analysis of Antifungal Activity of Crude Extracts (CEs) and Biologically Synthesized Gold Nanoparticles (CEs + AuNPs) Against Candida albicans}

As a pre-screening for the biofilm formation assay, antifungal activity was assessed. The absence of zone of inhibition is required for the subsequent biofilm formation assay to rule out antifungalmediated decrease in virulence factor production (Fernando and Judan Cruz, 2020; Velasco et al., 2020). Samples with antifungal activities shall not be included in the biofilm formation assay. The protocol of Fernando and Judan Cruz (2020) was used with some modifications. Sterile paper discs $(5 \mathrm{~mm})$ were soaked and air dried on sterilized petri plates under a biosafety laminar flow. Prepared media of corn meal agar on petriplates were swabbed with fungal culture. Air dried discs with treatments were seeded on plates; Ketoconazole served as positive control whereas sterile distilled water served as negative control. Plates were incubated at $37^{\circ} \mathrm{C}$ for $24-48 \mathrm{~h}$ and were observed for the appearance of the zone of inhibition.

\section{Microtiter Plate Biofilm Formation Assay}

The effect of CEs and CEs + AuNPs on biofilm formation was measured using a microtiter plate assay. Overnight cultures of
C. albicans with a volume of $180 \mu \mathrm{l}$ were added with $20 \mu \mathrm{l}$ of each treatment and were transferred to 96-well microtiter plates and incubated at $37^{\circ} \mathrm{C}$ for $40 \mathrm{~h}$ without shaking. After the incubation period, the microtiter plates were washed with sterile distilled water five times to discard planktonic cells. These were air dried for $45 \mathrm{~min}$ and stained with $150 \mu \mathrm{l}$ of $1 \%$ crystal violet for $45 \mathrm{~min}$ (Fernando and Judan Cruz, 2020). Plates were rinsed with sterile distilled water five times.

To quantify the biofilm, $200 \mu \mathrm{l}$ of $95 \%$ ethanol was added to destain the wells. From each well, $100 \mu \mathrm{l}$ were transferred to a new microtiter plate. Optical Density (OD) values were determined at $595 \mathrm{~nm}$ (Djordjevic et al., 2002) using UV-visible spectrophotometer (Biotek Instruments, Inc., United States).

\section{Gene Expression Analysis}

Treatments with significant inhibition in biofilm formation were subjected to gene expression analysis. RNA extraction was done following the RNA extraction kit manufacturer's protocol (Promega Corp.) with modifications. The expression of HSP90 and Bcr1 in C. albicans was determined through qRT-PCR analysis using Bio-Rad CFX96 Real-Time System Thermal Cycler and KAPA One Step RT-PCR kit (KAPA Biosystems). The specific primers used were: HSP90F 5' CGATGAATATGCCATGACT, HSP90R 5' TCCATAGCAGATTCTCCAG 3' (Mi-Kyung et al., 2004); BcrlF 5' GGCTGTCCATGTTGTTGTTG 3', BcrlR 5' GAGCACGCATCTATGGCTTA 3' (Alves et al., 2000); and the internal standard 16SF 5'ATGGCCGTTCTTAGTTGGTG 3', 16SR 5' GCCAAGGCTTATACTCGCTG 3' (Zhang et al., 2000). The qRT-PCR program was as follows: incubation at $42^{\circ} \mathrm{C}$ for $5 \mathrm{~min}$ for reverse transcription; $95^{\circ} \mathrm{C}$ for $1 \mathrm{~min}$; followed by 45 cycles of $95^{\circ} \mathrm{C}$ for $10 \mathrm{~s}, 60^{\circ} \mathrm{C}$ for $30 \mathrm{~s}$, and $72^{\circ} \mathrm{C}$ for $20 \mathrm{~s}$ (Nailis et al., 2006).

\section{Statistical Analysis}

Significant differences in OD values were analyzed via independent sample Tukey's Honest Significant Difference Test with 0.05 level of significance. For the gene expression analysis, $\mathrm{Ct}$ values were analyzed using the $2^{-\Delta \Delta C T}$ (Livak) method (Livak and Schmittgen, 2001). The statistical analysis for the gene expression was performed with the use of Kruskal-Wallis test (non-parametric ANOVA).

\section{RESULTS}

\section{Antifungal Activity of CEs and CEs + AuNPs Against C. albicans}

None of the CEs and CEs + AuNPs showed antifungal activity against $C$. albicans, hence, all samples were evaluated for its effects on biofilm formation.

\section{Inhibitory Effect of CEs and AuNPs on Biofilm Formation of C. albicans}

The optical density (OD) values of the C. albicans clinical isolate culture treated with 13 CEs namely $H$. vulgaris leaf (0.065 mg/ml); M. micrantha leaf $(0.062 \mathrm{mg} / \mathrm{ml})$; C. pentandra 
leaf $(0.066 \mathrm{mg} / \mathrm{ml}) ;$ C. winterianus Leaf $(0.063 \mathrm{mg} / \mathrm{ml}) ;$ S. alata $(0.063 \mathrm{mg} / \mathrm{ml}) ; U$. lobata leaf $(0.065 \mathrm{mg} / \mathrm{ml}) ;$ D. philippinensis leaf $(0.080 \mathrm{mg} / \mathrm{ml}) ;$ P odorata bark $(0.060 \mathrm{mg} / \mathrm{ml}) ;$ S. jamaicensis leaf $(0.067 \mathrm{mg} / \mathrm{ml}) ;$ E. indica roots $(0.067 \mathrm{mg} / \mathrm{ml}) ;$ D. esculentum $(0.083 \mathrm{mg} / \mathrm{ml}) ;$ E. indica L. leaf $(0.067 \mathrm{mg} / \mathrm{ml})$; and P. urinaria L. $(0.067 \mathrm{mg} / \mathrm{ml})$ showed significantly lower OD values in biofilm formation compared to the negative control (no extract) with a value of $0.19 \mathrm{mg} / \mathrm{ml}$ (Table 1). In contrast, two (2) CEs showed significantly higher OD values when compared to the control: D. philippinensis $(0.12 \mathrm{mg} / \mathrm{ml})$ bark and $P$. odorata leaf $(0.19 \mathrm{mg} / \mathrm{ml})$. These showed no QSI activity with increased formation of biofilm.

The OD values of $14 \mathrm{CEs}+$ AuNPs showed significant decrease in C. albicans biofilm formation compared to the control (Table 1) with the following values: H. vulgaris $(0.080 \mathrm{mg} / \mathrm{ml})$; M. micrantha leaf $(0.067 \mathrm{mg} / \mathrm{ml}) ; D$. philippinensis bark $(0.067 \mathrm{mg} / \mathrm{ml})$; C. pentandra leaf $(0.067 \mathrm{mg} / \mathrm{ml})$; C. winterianus leaf $(0.067 \mathrm{mg} / \mathrm{ml}) ; S$. alata $(0.063 \mathrm{mg} / \mathrm{ml}) ; U$. lobata leaf $(0.065 \mathrm{mg} / \mathrm{ml}) ;$ P. odorata bark $(0.082 \mathrm{mg} / \mathrm{ml}) ;$ S. jamaicensis leaf $(0.074 \mathrm{mg} / \mathrm{ml}) ; E$. indica $(0.067 \mathrm{mg} / \mathrm{ml}) ; P$. odorata leaf $(0.072 \mathrm{mg} / \mathrm{ml}) ; D$. esculentum $(0.073 \mathrm{mg} / \mathrm{ml}) ;$ E. indica leaf (0.067 mg/ml); P. urinaria leaf $(0.071 \mathrm{mg} / \mathrm{ml})$.

\section{Downregulation of Bcr1 and HSP9O as Affected by CEs and CEs + AuNPs}

The CEs and CEs + AuNPs that showed significantly lower biofilm formation were subjected to gene expression analysis. Bcrl expression analysis showed down regulation in all CEs and CEs + AuNPs treatments with significantly lower biofilm formation in the virulence assay (Figure 1). The expression of Bcrl in C. albicans was significantly downregulated in association with the CEs of $H$. vulgaris (0.071), M. micrantha

TABLE 1 | Biofilm inhibition in C. albicans as affected by CEs and CEs + AuNPs.

\begin{tabular}{lcc}
\hline Scientific name & Crude extract & $\begin{array}{c}\text { Biologically } \\
\text { synthesized gold } \\
\text { nanoparticles }\end{array}$ \\
\hline H. vulgaris & $0.065^{\star a}$ & $0.080^{\star b}$ \\
M. micrantha & $0.062^{\star a}$ & $0.067^{\star b}$ \\
D. philippinensis (bark) & 0.116 & $0.066^{\star}$ \\
C. pentandra & $0.066^{\star}$ & $0.066^{\star}$ \\
C. winterianus & $0.064^{\star}$ & $0.066^{\star}$ \\
S. alata & $0.063^{\star}$ & $0.062^{\star}$ \\
U. lobata & $0.065^{\star}$ & $0.065^{\star}$ \\
D. philippinensis (leaves) & $0.080^{\star}$ & 0.135 \\
P. odorata (bark) & $0.06^{\star a}$ & $0.082^{\star b}$ \\
S. jamaicensis & $0.067^{\star}$ & $0.074^{\star}$ \\
E. indica (roots) & $0.066^{\star}$ & $0.068^{\star}$ \\
P. odorata (leaves) & 0.186 & $0.072^{\star}$ \\
D. esculentum & $0.083^{\star a}$ & $0.072^{\star b}$ \\
E. indica (leaves) & $0.067^{\star}$ & $0.070^{\star}$ \\
P. urinaria & $0.067^{\star}$ & $0.071^{\star}$ \\
Control & 0.190 & 0.190 \\
\hline . & &
\end{tabular}

In columns, $\left(^{*}\right)$ indicates significantly lower O.D. value in biofilm formation compared the control; Different letter superscripts among rows indicate significant difference. leaf (1.036), C. pentandra leaf (3.033), C. winterianus Leaf (0.403), S. alata (7.459), U. lobata leaf (0.292), D. philippinensis leaf (0.485), P. odorata bark (3.792), S. jamaicensis leaf (0.87), E. indica roots (0.437), D. esculentum (0.115), E. indica leaf (0.213), and P. urinaria leaf (3.772) as compared to the control with no plant extract used (15.44). Significant downregulation of the Bcrl gene was also observed in CEs + AuNPs of H. vulgaris (0.711), M. micrantha (10.496), D. philippinensis bark (4.567), C. pentandra leaf (0.223), C. winterianus Leaf (12.898), S. alata (0.799), U. lobata leaf (0.490), P. odorata bark (0.161), $S$. jamaicensis leaf $(0.780), E$. indica roots $(0.140), P$. odorata leaf (0.835), D. esculentum (0.086), E. indica leaf (0.87), and $P$. urinaria (0.87) (Figure 1).

HSP90 also showed down regulation in C.albicans treated with CEs and CEs + AuNPs that showed lower biofilm formation values. The expression of HSP90 was significantly downregulated in association with the CEs of $H$. vulgaris (0.16), M. micrantha leaf (0.679), C. pentandra leaf (1.473), C. winterianus leaf (0.288), S. alata (21.274), U. lobata leaf (0.683), D. philippinensis leaf (0.396), P. odorata bark (0.289), S. jamaicensis leaf (0.246), E. indica roots $(0.350), D$. esculentum $(0.283)$, E. indica leaf (0.248), and P. urinaria (0.221) as compared to the control with no plant extract used (23.056) (Figure 2). Significant downregulation of the HSP90 was also observed in CEs + AuNPs of $H$. vulgaris (0.099), M. micrantha (0.277), D. philippinensis bark (1.640), C. pentandra leaf (0.523), C. winterianus Leaf (0.674), S. alata (21.161), U. lobata leaf (0.463), P. odorata bark (0.024), S. jamaicensis leaf (0.287), E. indica roots (0.476), P. odorata leaf (0.115), D. esculentum (0.462), E. indica leaf (0.407), and P. urinaria (0.377) (Figure 2).

\section{DISCUSSION}

Inhibition of biofilm formation by the ethnobotanical CEs and CEs + AuNPs in this study may be attributed to the presence of known QSI agents that are recognized to negatively affect signal receptors (Kalia, 2013) responsible for the functional communication between adjacent cells (Miller and Bassler, 2001). The Ilongot-Eǵongot ethnobotanicals evaluated in this study are known to possess active groups of metabolites against QS such as: flavonoids, saponins and tannins in C. pentandra (Friday et al., 2011); flavonoid, saponins, tannins, alkaloids, and geranoil in C. winterianus (Anosike et al., 2012); S. alata contains flavonoid, saponins, tannins, alkaloids, and terpenes (Sule et al., 2011), U. lobata with saponins, tannins, alkaloid, and terpenoid (Fagbohun et al., 2012), and P. odorata with flavonoid, saponins, and terpenoids (Chichioco-Hernandez and Paguigan, 2009). The isolated terpene and sterol compounds in C. pentandra attenuated virulence factors in $P$. aeruginosa (Muñoz-Cázares et al., 2017). Only the major metabolites have been evaluated and reported against QS while the specific bioactive components of the ethnobotanicals in this study have not yet been elucidated and presents an avenue for research in detailed phytochemistry.

The well documented mechanism of QSI action of phytochemicals is linked to their similarity in the chemical structure to QS signals and to their capacity to suppress 




FIGURE 1 | Mean Ct values of Bcr1 in C. albicans with CEs and CEs + AuNPs. (1) Control (2) H. vulgaris (3) M. micrantha (4) D. philippinensis (bark) (5) C. pentandra (6) C. winterianus (7) S. alata (8) U. lobata (9) D. philippinensis (leaf) (10) P. odorata (bark) (11) S. jamaicensis (leaf) (12) E. Indica (root) (13) E. esculenta (14) E. indica (leaf) (15) P. urinaria.

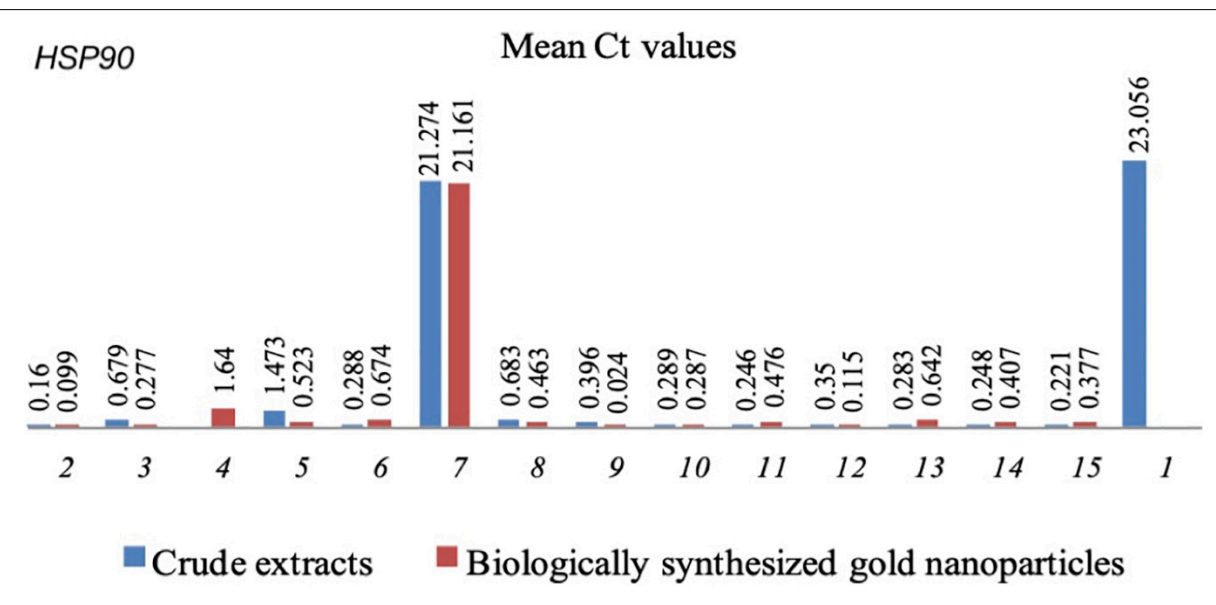

FIGURE 2 | Mean Ct values of HSP90 in C. albicans with CEs and CEs + AuNPs. (1) Control (2) H. vulgaris (3) M. micrantha (4) D. philippinensis (bark) (5) C. pentandra (6) C. winterianus (7) S. alata (8) U. lobata (9) D. philippinensis (leaf) (10) P. odorata (bark) (11) S. jamaicensis (leaf) (12) E. Indica (root) (13) E. esculenta (14) E. indica (leaf) (15) P. urinaria.

signal receptors (Kalia, 2013). Plants have been known to contain phytochemicals associated with QSI activities and is considered as one of the most powerful natural sources of isolated QSI compounds. These compounds can reduce microbe pathogenicity (Rasmussen and Givskov, 2006) owing to their ability to block in intra and inter-species QS communication systems (Teplitski et al., 2000). This ability of natural compounds to suspend QS systems can serve as a defense strategy to fight against microbial penetration. As a prospective source of antivirulence agents (Rawat et al., 2016) that are safe for human health, it owes its advantage to its chemical stability and highly effective low-molecular-mass molecules (Rasmussen and Givskov, 2006) with non-toxic inhibitors of QS (Hentzer et al., 2003).

Evaluating the effects of potential QSI agents on the molecular mechanisms directing biofilm formation is a critical strategy to facilitate advances in novel antivirulence therapies. In this study, the expression of 2 biofilm-linked genes, Bcrl and HSP90, as affected by CEs and CEs + AuNPs were evaluated.
Molecular expression analyses showed downregulation of both $B c r 1$ and HSP 90 as affected by CEs and CEs + AuNPs. Expression of Bcrl and its downstream genes influences adhesion and arrangement of the polysaccharide matrix in C. albicans. Hence, downregulation of $B c r 1$ affects the formation of the complex biofilm and its multi- dimensional polysaccharide matrix (Douglas, 2003); this means that biofilm formation will be repressed or will not yield a thick extracellular matrix. On the other hand, by targeting HSP90 downregulation, dispersion will be suppressed and cell signals critical to biofilm formation will be blocked without developing resistance to existing antifungals (Robbins et al., 2011). The compounds in CEs and CEs + AuNPs may have acted as QSI molecules that have blocked the pathway of Bcrl and HSP90, hence, its downregulation. This showed that the production of QS molecules was reduced and have decreased in the expression of a specific receptor or transcription factor (Nobile et al., 2006). It has been recognized that expression of QS genes is important in the production of virulence factors such as the formation of biofilm, and this information gives 
improved understanding of the function of the genes associated with its morphological features (Nobile et al., 2006). Thus, downregulation of Bcr 1 and HSP90 by the CEs and CEs + AuNPs not only have the potential to inhibit the growth of biofilm but also that of antifungal resistance. Blocking or minimizing expression of these genes provides a key strategy to developing drugs for C. albicans management.

The efficiency on the use of nanoparticles was demonstrated in this study wherein treatments with CEs + AuNPS showed significantly lower biofilm formation in comparison with CEs alone. The CEs + AuNPs conjugation length and intensities decreased from 595 to $544 \mathrm{~nm}$ which signifies the decrease in size. The study of Emmanuel et al. (2017) demonstrates that the decrease in the conjugation length and intensities of AuNPs indicates the decrease in particle size. The formation of CEs + AuNPs in this study were monitored by analyzing the excitation due to the applied electromagnetic field of Surface Plasmon resonance (SPR) and absorption values. SPR peaks attained in UV-vis spectroscopy is one of the versatile techniques to confirm the formation of metal NPs and was generated due to the coherence of electrons on the surface of AuNPs. The shift to the blue or red in the $\lambda$ max of the SPR peak could be related to the obtained morphology of NPs that has various shapes, sizes or extract dependencies of formed AuNPs (Vellaichamy and Periakaruppan, 2016; Emmanuel et al., 2017; Kanwal et al., 2018). The color change in reaction from yellowish to pink red and decreased conjugation length confirms the formation of CE + AuNPs (Mukherjee et al., 2016; Ovais et al., 2016). Furthermore, the $\mathrm{pH}$ of the solution increased from 6.0 to 6.5 after the addition of the crude ethnobotanical extracts indicating to a more stable state of the gold nanoparticles. The stability of gold nanoparticles is pH-responsive (Park et al., 2019) and its stability is $\mathrm{pH}$-dependent, as shown in studies using natural compound for its synthesis (Tyagi et al., 2011).

The development of methods for integrated solution and control of pathogenic virulence and drug resistance has led many scientists to evaluate nanotechnology for efficient delivery of anti-pathogenic drugs from the natural compounds. Since its revolution, nanotechnology has been used to improve the uptake of soluble drugs (Ould-Ouali et al., 2005) due to their extremely reduced dimensions and somewhat large surface area (Kamat et al., 2002). Its safety also accompanies its advantages as it produces environmentally non-toxic molecules (Khatami et al., 2017). The results of this study may indicate expedited delivery system of the compounds through extremely reduced particle size and increased surface area that facilitates entry of compounds to the phospholipid- and glycoprotein-embedded cell membrane (Cabrera et al., 2017).

This study has shown that ethnobotanicals are a promising source of antipathogenic agents. Except for a few studies, these plants largely remain unexplored for their pharmacological potential. A number of studies have shown proof that ethnobotanicals possesses QSI actions in virulence factors in bacteria such as biofilm formation (Judan Cruz et al., 2018; Fernando and Judan Cruz, 2020; Fernando et al., 2020; Velasco et al., 2020; Santos et al., 2021), coagulase (Vias et al., 2018; Salamanca et al., 2019), pyocyanin production
(Barrogo et al., 2018; Limos et al., 2018a), swarming motility (Barrogo et al., 2018; Limos et al., 2018a; Padilla et al., 2018), DNase (Limos et al., 2018b), and $\alpha$ - Hemolysin (Limos et al., 2018b; Vergara et al., 2018), showing the immense prospects of tapping these plants for antivirulence drug design. The QSI actions of the ethnobotanicals were confirmed through expression analyses of QS-linked genes such as lasR, rhlR, ahyR, and $\operatorname{agr} A$.

Targeting virulence factors is a promising approach to design new and effective antifungal therapies (Mayer et al., 2013). Biofilm is one of the QS-regulated virulence factors that contribute to the pathogenicity as well as to the increasing development of fungal drug resistance in C. albicans. Despite the existing antifungal drugs, fungal resistance is evolving due to long term exposure. A novel approach for its control is to obtain plant bioactive compounds to create a wide variety of drugs (Cruz et al., 2007) that targets the formation of biofilm. Recently, a number of antifungal drugs have been designed to contain natural derivatives or compounds mimicking natural products (Newman, 2008). In C. albicans, numerous plant extracts and its compounds are already known to change its adhesion mechanics (Ahmad and Aqil, 2007); adhesion being the first step in its biofilm formation and significantly contributes to C. albicans pathogenicity (Mukherjee et al., 2003).

Diverse natural products are recognized to inhibit biofilm formation through scientific validations and studies. Therefore, the discovery of plant bioactive compounds that controls pathogenicity becomes a fundamental strategy (Ahmad and Aqil, 2007) toward C. albicans management. This paper highlights the great pharmacological potential of these ethnobotanical extracts for developing efficient therapeutic agents against C. albicans without the risk of developing drug resistance. This potential can be further improved through nanotechnology. This new understanding can be used to direct the discovery of novel approaches for preventing and controlling complex and resistant biofilms.

\section{DATA AVAILABILITY STATEMENT}

The original contributions presented in the study are included in the article/supplementary material, further inquiries can be directed to the corresponding author/s.

\section{AUTHOR CONTRIBUTIONS}

KJC provided the concept and design of the study, wrote the first and final drafts of the manuscript, and performed laboratory works. EA wrote the first draft of the manuscript, performed laboratory works, and provided laboratory materials. SF performed laboratory works, wrote a section of the manuscript, and performed statistical analyses. KW wrote a section of the manuscript, provided a portion of the laboratory funding, and supervised laboratory works. All authors contributed to manuscript revision, read, and approved the submitted version. 


\section{ACKNOWLEDGMENTS}

We are deeply grateful for their permission and support of the Ilongot-Eǵongot ethnic community of Maria Aurora, Aurora, Philippines. We also acknowledge the following for the use of their laboratories: Molecular Biology and Biotechnology Laboratory of the College of Fisheries, Philippine Rice Research Institute and the Department of Biological Sciences, and College

\section{REFERENCES}

Ahmad, I., and Aqil, F. (2007). In vitro efficacy of bioactive extracts of 15 medicinal plants against ES $\beta$ L-producing multidrug-resistant enteric bacteria. Microbiol. Res. 162, 264-275. doi: 10.1016/j.micres.2006.06.010

Alves, T. M. A., Silva, A. F., Brandao, M., Grandi, T. S. M., Smania, E. F., Smania, A. Jr., et al. (2000). Biological screening of Brazilian medicinal plants. Mem. Inst. Oswaldo Cruz 95, 367-373. doi: 10.1590/S0074-02762000000300012

Anosike, C. A., Ogili1, O. B., Nwankwo, O. N., and Eze, E. A. (2012). Phytochemical screening and antimicrobial activity of the petroleum ether, methanol and ethanol extracts of Ceiba pentandra stem bark. J. Med. Plant Res. 6, 5743-5747. doi: 10.5897/JMPR12.978

Balberona, A. N., Noveno, J. J., Angeles, M. G. B., Santos, R. I., Cachin, E., and Judan Cruz, K. G. (2018). Ethnomedicinal plants utilized by the ilongote? ongot community of bayanihan, maria aurora, aurora, Philippines. Int. J. Agric. Technol. 14, 145-159.

Barrogo, K. N., Jacinto, W. R., and Judan Cruz, K. J. (2018). Quorum sensinginhibition activities of philippine ethnobotanicals against virulence factors in Pseudomonas aeruginosa. Int. J. Biosci. 13, 173-182.

Borges, A., and Simoes, M. (2019). Quorum sensing inhibition by marine bacteria. Mar. Drugs 17:427. doi: 10.3390/md17070427

Cabrera, G. F., Balbin, M. M., Eugenio, P. J., Zapanta, C. S., Monserate, J. J., Salazar, J. R., et al. (2017). Green synthesis of gold nanoparticles reduced and stabilized by sodium glutamate and sodium dodecyl sulphate. Biochem. Biophys. Res. Commun. 484, 774-780.

Chichioco-Hernandez, C. L., and Paguigan, N. D. (2009). Antimutagenic potential and phytochemical anaylsis of selected Philippine plants. Pharmacogn. Mag. 5, 388-393.

Cruz, M. C., Santos, P. O., Barbosa, A. M. Jr., de Me'lo, D. L., Alviano, C. S. Antoniolli, A. R., et al. (2007). Antifungal activity of Brazilian medicinal plants involved in popular treatment of mycoses. J. Ethnopharmacol. 111, 409-412. doi: 10.1016/j.jep.2006.12.005

Daniel, M. C., and Astruc, D. (2004). Gold nanoparticles: assembly, supramolecular chemistry, quantum-size-related properties, and applications toward biology, catalysis, and nanotechnology. Am. Chem. Soc. 104, 293-346. doi: 10.1021/ cr030698

Djordjevic, D., Wiedmann, M., and Mclandsborough, L. A. (2002). Microtiter plate assay for assessment of Listeria monocytogenes biofilm formation. Appl. Environ. Microbiol. 68, 2950-2958. doi: 10.1128/AEM.68.6.2950/break2958.2002

Douglas, L. J. (2003). Candida biofilms and their role in infection. Trends Microbiol. 11, 30-36. doi: 10.1016/S0966-842X(02)00002-1

Duo, M., Zhang, M., Luk, Y., and Ren, D. (2010). Inhibition of Candida albicans growth by brominated furanones. Appl. Microbiol. Biotechnol. 85, 1551-1563. doi: 10.1007/s00253-009-2174-6

Emmanuel, R., Saravanan, M., Ovais, M., Padmavathy, S., Shinwari, Z. K., and Prakash, P. (2017). Antimicrobial efficacy of drug blended biosynthesized colloidal gold nanoparticles from justicia glauca against oral pathogens: a nanoantibiotic approach. Microb. Pathog. 113, 295-302. doi: 10.1016/j.micpath. 2017.10.055

Fagbohun, E. D., Asare, R. R., and Egbebi, A. O. (2012). Chemical composition and antimicrobial activities of Urena lobata L. (Malvaceae). J. Med. Plants Res. 6, 2256-2260. doi: 10.5897/JMPR10.233

Fanning, S., Xu, W., Beaurepaire, C., Suhan, J. P., Nantel, A., and Mitchell, A. P. (2012). Functional control of the Candida albicans cell wall by catalytic protein of Science, Central Luzon State University. All facilities are located at the Science City of Muñoz, Nueva Ecija, Philippines.

\section{DEDICATION}

This work is dedicated to the Ilongot-Eǵongot ethnic community of Maria Aurora, Aurora, Philippines.

kinase A subunit Tpk1. Mol. Microbiol. 86, 284-302. doi: 10.1111/j.1365-2958. 2012.08193

Fernando, S. I. D., and Judan Cruz, K. G. (2020). Ethnobotanical biosynthesis of gold nanoparticles and its downregulation of quorum sensing-linked AhyR gene in Aeromonas hydrophila. SN Appl. Sci. 2:570. doi: 10.1007/s42452-020-2368-1

Fernando, S. I. D., Judan Cruz, K. G., and Watanabe, K. (2020). Quorum sensinglinked agrA expression by ethno-synthesized gold nanoparticles in Tilapia Streptococcus agalactiae biofilm formation. BioNanoScience 10, 696-704. doi: 10.1007/s12668-020-00758-6

Friday, T., Omale, J., Olusegun, O., and Gabriel, A. (2011). Investigations on the nutritional and medicinal potentials of Ceiba pentandra leaf: a common vegetable in Nigeria. Int. J. Plant Physiol. Biochem. 3, 95-101.

Gao, M., Wang, H., and Zhu, L. (2016). Quercetin assists fluconazole to inhibit biofilm formations of fluconazole- resistant Candida Albicans in in vitro and in vivo antifungal managements of vulvovaginal candidiasis. Cell. Physiol. Biochem. 40, 727-742.

Gao, S., Liu, G., Li, J., Chen, J., Li, L., Li, Z., et al. (2020). Antimicrobial activity of lemongrass essential oil (Cymbopogon flexuosus) and its active component citral against dual- species biofilms of Staphylococcus aureus and Candida species. Front. Cell. Infect. Microbiol. 10:603858. doi: 10.3389/fcimb.2020.603858

Hall-Stoodley, L., Costerton, J. W., and Stoodley, P. (2004). Bacterial biofilms: from the natural environment to infectious diseases. Nat. Rev. Microbiol. 2, 95-108.

Hentzer, M., Wu, H., Andersen, J. B., Riedel, K., Rasmussen, T. B., Bagge, N., et al. (2003). Attenuation of Pseudomonas aeruginosa virulence by quorum sensing inhibitors. EMBO J. 22, 3803-3815. doi: 10.1093/emboj/cdg366

Judan Cruz, K. G., Gatchalian, J. J. G., and Jacinto, W. R. (2018). Philippine ethnobotanicals inhibit quorum sensing-controlled biofilm formation in Pseudomonas aeruginosa. Int. J. Biol. Pharm. Allied Sci. 7, 527-537.

Kalia, V. C. (2013). Quorum sensing inhibitors: an overview. Biotechnol. Adv. 31, 224-245. doi: 10.1016/j.biotechadv.2012.10.004

Kamat, P. V., Barazzouk, S., and Hotchandani, S. (2002). Electrochemical modulation of fluorophore emission on a nanostructured gold film. Angew. Chem. Int. Ed. Engl. 41, 2764-2767. doi: 10.1002/1521-3773

Kanwal, U., Bukhari, N. I., Ovais, M., Abass, N., Hussain, K., and Raza, A. (2018). Advances in nano-delivery systems for doxorubicin: an updated insight. J. Drug Target. 26, 296-310. doi: 10.1080/1061186X.2017.1380655

Khatami, M., Heli, H., Jahani, P. M., Azizi, H., and Lima, N. M. (2017). Copper/copper oxide nanoparticles synthesis using Stachys lavandulifolia and its antibacterial activity. IET Nanobiotechnol. 11, 709-713. doi: 10.1049/iet-nbt. 2016.0189

Lee, J. H., Kim, Y. G., Choi, P., Ham, J., Park, J. G., and Lee, J. (2018). Antibiofilm and antivirulence activities of 6-gingerol and 6-shogaol against Candida albicans due to hyphal inhibition. Front. Cell. Infect. Microbiol. 8:299. doi: 10.3389/fcimb.2018.00299

Lewis, K. (2020). The science of antibiotic discovery. Cell 181, 29-45. doi: 10.1016/ j.cell.2020.02.056

Limos, G. B.B., Judan Cruz, K. G., and Jacinto, W. R. (2018a). Quorum sensing inhibition bioactivities of philippine ethnobotanicals against Pseudomonas aeruginosa. Int. J. Pure Appl. BioSci. 6, 47-56.

Limos, G. B. B., Jacinto, W. R., and Judan Cruz, K. G. (2018b). Philippine ethnobotanicals inhibit virulence factors in Staphylococcus aureus. Int. J. Biosci. $13,178-187$.

Livak, K. J., and Schmittgen, T. D. (2001). Analysis of relative gene expression data using real-time quantitative PCR and the 2(-Delta Delta C(T)) Method. Methods 25, 402-408. 
Lohse, M. B., Gulati, M., Johnson, A. D., and Nobile, C. J. (2018). Development and regulation of single- and multi-species Candida albicans biofilms. Nat. Rev. Microbiol. 16, 19-31. doi: 10.1038/nrmicro.2017.107

Maeda, T., Garcia-Contreras, R., Pu, M., Sheng, L., Garcia, L. R., Tomas, M., et al. (2012). Quorum quenching quandary: resistance to antivirulence compounds. ISME J. 6, 493-501. doi: 10.1038/ismej.2011.122

Mathe, L., and Van Djick, P. (2013). Recent insights into Candida albicans biofilm resistance mechanisms. Curr. Genet. 59, 251-264.

Mayer, F. L., Wilson, D., and Hube, B. (2013). Candida albicans pathogenicity mechanisms. Virulence 4, 119-128.

Mi-Kyung, L., Williams, L. E., Warnock, D. W., and Arthington-Skaggs, B. A. (2004). Drug resistance genes and trailing growth in Candida albicans isolates. J. Antimicrob. Chemother. 53, 217-224. doi: 10.1093/jac/dkh040

Miller, M. B., and Bassler, B. (2001). Quorum sensing in bacteria. Annu. Rev. Microbiol. 55, 165-199.

Moran, G. P., Coleman, D. C., and Sullivan, D. J. (2012). Candida albicans versus Candida dubliniensis: why is C. albicans more pathogenic? Int. J. Microbiol. 7:205921.

Mukherjee, P. K., Chandra, J., Kuhn, D. M., and Ghannoum, M. A. (2003). Mechanism of fluconazole resistance in Candida albicans biofilms: phase specific role of efflux pumps and membrane sterols. Infect. Immun. 71, 43334340. doi: 10.1128/IAI.71.8.4333-4340

Mukherjee, S., Sau, S., Madhuri, D., Bollu, V. S., Madhusudana, K., Sreedhar, B., et al. (2016). Green synthesis and characterization of monodispersed gold nanoparticles: toxicity study, delivery of doxorubicin and its bio-distribution in mouse model. J Biomed. Nanotechnol. 12, 165-181. doi: 10.1166/jbn.2016.2141

Muñoz-Cázares, N., Aguilar-Rodrì̀guez, S., Garciìa- Contreras, R., SotoHernaìndez, M., Martiìnez-Vaìzquez, M., Palma-Tenango, M., et al. (2017). Phytochemical screening and anti- virulence properties of Ceiba pentandra and Ceiba aesculifolia (Malvaceae) bark extracts and fractions. Botanical Sci. 96, 415-425.

Nailis, H., Coenye, T., Nieuwerburgh, V. F., Deforce, D., and Nelis, H. J. (2006). Development and evaluation of different normalization strategies for gene expression studies in Candida albicans biofilms by real-time PCR. BMC Mol. Biol. 7:25. doi: 10.1186/1471-2199-7-25

Newman, D. J. (2008). Natural products as leads to potential drugs: An old process or the new hope for drug discovery? J. Med. Chem. 51, 2589-2599. doi: 10.1021/ jm0704090

Nobile, C. J., Andes, D. R., Nett, J. E., Smith, F. J. Jr., Yue, F., Phan, Q. T., et al. (2006). Critical role of Bcrl-dependent adhesions in C. albicans biofilm formation in vitro and in vivo. PLoS Pathog. 2:63.

Ould-Ouali, L., Noppe, M., Langlois, X., Willems, B., Te Riele, P., Timmerman, P., et al. (2005). Self-assembling PEGp (CL-co-TMC) copolymers for oral delivery of poorly watersoluble drugs: a case study with risperidone. J. Controlled Release 102, 657-668. doi: 10.1016/j.jconrel.2004.10.022

Ovais, M., Khalil, A. T., Raza, A., Khan, M. A., Ahmad, I., Islam, N. U., et al. (2016). Green synthesis of silver nanoparticles via plant extracts: beginning a new era in cancer theranostics. Nanomedicine 11, 3157-3177.

Padilla, K. G. V., Jacinto, W. R., and Judan Cruz, K. G. (2018). Philippine ethnobotanicals inhibit quorum sensing-mediated swarming motility in Pseudomonas aeruginosa. Adv. BioRes. 9, 7-13.

Park, S., Lee, W. J., Park, S., Choi, D., Kim, S., and Park, N. (2019). Reversibly pHresponsive gold nanoparticles and their applications for photothermal cancer therapy. Sci. Rep. 9:20180. doi: 10.1038/s41598-019-56754-8

Pearl, L. H., and Prodromou, C. (2006). Structure and mechanism of the Hsp90 molecular chaperone machinery. Annu. Rev. Biochem. 75, 271-294. doi: 10. 1146/annurev.biochem.75.1030041.14

Peman, J., Canton, E., and Espinel-Ingroff, A. (2009). Antifungal drug resistance mechanisms. Expert Rev. Anti Infect. Ther. 7, 453-460.

Pereira, R., dos Santos Fontanelle, R. O., de Brito, E. H. S., and de Morais, S. M. (2020). Biofilm of Candida albicans: formation, regulation and resistance. J. Appl. Microbiol. 2020, 1-12. doi: 10.1111/jam.14949

Pfaller, M. A. (2012). Antifungal drug resistance: mechanisms, epidemiology, and consequences for treatment. Am. J. Med. 125, 3-13. doi: 10.1016/j.amjmed. 2011.11.001

Rasmussen, T. B., and Givskov, M. (2006). Quorum sensing inhibitors: a bargain of effects. Microbiology 152, 895-904. doi: 10.1099/mic.0.28601-0
Rawat, S., Jugran, A. K., Bahukhandi, A., Bahuguna, A., Bhatt, I. D., Rawal, R. S., et al. (2016). Anti-oxidant and anti-microbial properties of some ethno-therapeutically important medicinal plants of Indian Himalayan Region. Biotechnology 6:154. doi: 10.1007/s13205-016-0470-2

Robbins, N., Uppuluri, P., Nett, J., Rajendran, R., Ramage, G., Lopez-Ribot, J. L., et al. (2011). Hsp90 governs dispersion and drug resistance of fungal biofilms. PLoS Pathog. 7:e1002257. doi: 10.1371/journal.ppat.1002257

Salamanca, G. T., Fernando, S. I. D., and Judan Cruz, K. G. (2019). agrA expression linked to quorum sensing-mediated coagulase formation using philippine ilongot ethnobotanicals against Staphylococcus aureus. Int. J. Biosci. 15, 33-41.

Santos, R. I., Jacinto, W. R., and Judan Cruz, K. G. (2021). Philippine ethnobotanicals downregulate las $R$ expression linked to quorum sensingmediated biofilm formation in Pseudomonas aeruginosa. J. Microbiol. Biotech. Food Sci. 10, 592-597. doi: 10.15414/jmbfs.2021.10.4.592-597

Shapiro, R. S., Uppuluri, P., Zaas, A. K., Collins, C., Senn, H., Perfect, J. R., et al. (2009). Hsp90 orchestrates temperature- dependent Candida albicans morphogenesis via Ras1-PKA signaling. Curr. Biol. 19, 621-629.

Silva, S., Negri, M., Henriques, M., Oliveira, R., Williams, D. W., and Azeredo, J. (2011). Adherence and biofilm formation of non- Candida albicans Candida species. Trends Microbiol. 19, 241-247. doi: 10.1016/j.tim.2011. 02.003

Srisawat, S. (2007). Effect of Some Thai Medicinal Plant Extracts on Antibacterial Activity of Periodontopathic bacteria and Their Anti-inflammatory Activity and Toxicity to Gingival Connective Tissue Fibroblast. Doctoral Dissertation. Bangkok: Prince of Songkla University.

Sule, W. F., Okonko, I. O., Omo-Ogun, S., Nwanze, J. C., Ojezele, M. O., Ojezele, O. J., et al. (2011). Phytochemical properties and in-vitro antifungal activity of Senna alata Linn. crude stem bark extract. J. Med. Plant. Res. 5, 176-183.

Teplitski, M., Robinson, J. B., and Bauer, W. D. (2000). Plants secrete substances that mimic bacterial Neacyl homoserine lactone signal activities and affect population density dependent behaviors in associated bacteria. Mol. Plant Microbe Interact. 13, 637-648. doi: 10.1094/MPMI.2000.13.6.637

Tyagi, H., Kushwaha, A., Kumar, A., and Aslam, M. (2011). pH-dependent synthesis of stabilized gold nanoparticles using ascorbic acid. Int. J. Nanosci. 10, 857-860. doi: 10.1142/S0219581X11009301

Velasco, A. T., Fernando, S. I. D., and Judan Cruz, K. G. (2020). lasR/rhlR expression linked to quorum sensing-mediated biofilm formation in Pseudomonas aeruginosa using gold nanoparticles synthesized with ethnobotanical extracts. BioNanoSci 10, 876-884. doi: 10.1007/s12668020-00757-7

Vellaichamy, B., and Periakaruppan, P. (2016). Ag nanoshell catalyzed dedying of industrial effluents. RSC Adv. 6, 31653-31660.

Vergara, K. G., Jacinto, W. R., and Judan Cruz, K. G. (2018). Quorumsensing mediated $\alpha$ - Hemolysin inhibition of philippine ethnobotanicals in Staphylococcus aureus. Int. J. Biol. Pharm. Allied Sci. 7, 1537-1550. doi: 10. 31032/IJBPAS/2018/7.8.4512

Vias, J. G., Jacinto, W. R., and Judan Cruz, K. G. (2018). Philippine ethnobotanicals inhibit formation of coagulase in Staphylococcus aureus. Adv. BioRes. 9, 1-6.

Zhong, S., and He, S. (2021). Quorum sensing inhibition or quenching in Acinetobacter baumannii: The novel therapeutic strategies for new drug development. Front. Microbiol. 12:558003. doi: 10.3389/fmicb.2021. 558003

Zhang, X., Essmann, M., Burt, E. T., and Bryan, L. (2000). Estrogen effects on Candida albicans: a potential virulence-regulating mechanism. J. Infect. Dis. 4, 1441-1446. doi: 10.1089/315406

Conflict of Interest: The authors declare that the research was conducted in the absence of any commercial or financial relationships that could be construed as a potential conflict of interest.

Copyright (c) 2021 Judan Cruz, Alfonso, Fernando and Watanabe. This is an openaccess article distributed under the terms of the Creative Commons Attribution License (CC BY). The use, distribution or reproduction in other forums is permitted, provided the original author(s) and the copyright owner(s) are credited and that the original publication in this journal is cited, in accordance with accepted academic practice. No use, distribution or reproduction is permitted which does not comply with these terms. 